\section{Módulo complexo de compósitos asfálticos com argila calcinada sob flexão a quatro pontos}

\section{Complex modulus of asphalt mix with calcined clay under four-point bending}

Antonio Cleiton Lopes da Silva ${ }^{1}$, Consuelo Alves da Frota ${ }^{1}$ Hidembergue Ordozgoith da Frota ${ }^{1}$

\author{
${ }^{1}$ Universidade Federal do Amazonas (UFAM), Grupo de Geotecnia - Av. General Rodrigo Octávio Jordão Ramos, 3000, \\ Manaus - AM \\ e-mail: cleiton.acls@hotmail.com; cafrota@ufam.edu.br; hfrota@ufam.edu.br
}

\begin{abstract}
RESUMO
Na análise mecanicista, o módulo complexo é um parâmetro de fundamental importância para construção de modelos constitutivos do comportamento do concreto asfáltico. Dentre as opções mais modernas para sua obtenção, encontram-se os testes de flexão a quatro pontos, amplamente difundidos na Europa e objeto do presente estudo. Realizou-se esse experimento para obtenção do módulo dinâmico e ângulo de fase, empregando-se condições representativas de Manaus (AM) no tocante ao agregado graúdo e temperatura, que na superfície dos pavimentos alcança em torno de $60^{\circ} \mathrm{C}$ por longas horas do dia. Como material graúdo, ante a escassez regional de agregado pétreo, utilizou-se o Agregado Sinterizado de Argila Calcinada (ASAC), alternativa promissora diante da abundância de matéria prima e viabilidade técnica e financeira. Como resultado obteve-se pontualmente o módulo dinâmico e ângulo de fase a diversas frequências e temperaturas. Por fim, consideradas as condições locais de temperatura e tráfego, o módulo dinâmico apresentou grandes variações, indicando queda de até 93,3\% em seu valor, situação em que o pavimento apresenta-se muito suscetível a deformações permanentes, problema recorrente nos pavimentos asfálticos locais.
\end{abstract}

Palavras-chave: módulo dinâmico, flexão a quatro pontos, agregado de argila calcinada, temperatura.

\begin{abstract}
In mechanistic analysis, the complex modulus is a fundamental parameter for the constitutive models of asphalt concrete. The four-point bending test, widely used in Europe, is among the most modern options for obtaining the complex modulus. In this study a four-point bending tests is carried out to obtain the dynamic modulus and phase angle of the asphalt concrete, employing Amazon representative conditions for the coarse aggregate and temperature on the road surface, which reaches almost $60{ }^{\circ} \mathrm{C}$ for many hours a day. As aggregate, taking into account the regional shortage of stone materials, we used the ASAC - Synthesized Calcined Clay Aggregate, a promising material due the abundance of raw materials and the technical and financial feasibility. As a result of the tests, it has been found the dynamic modulus and the phase angle at different frequencies and temperatures. Considering the local conditions of temperature and traffic, the dynamic module presented abrupt change, showing a drop of up to $93.3 \%$ in value, with the surface appearing very susceptible to permanent deformation, recurring problem in local asphalt pavements.
\end{abstract}

Keywords: dynamic module, the four-point bending, calcined clay aggregate, temperature.

\section{INTRODUÇÃO}

Os pavimentos rodoviários compreendem um sistema complexo de multicamadas formado por diferentes materiais. São submetidos a esforços provenientes de inúmeras combinações de carregamento oriundos do tráfego de veículos e ao influxo de distintas condições ambientais [1].

No tocante aos revestimentos asfálticos, costuma-se utilizar em sua composição materiais pétreos, como a brita proveniente de rochas, ou, alternativamente, diante de sua escassez (caso da região amazônica), 
o seixo rolado proveniente do leito dos rios. Esta solução causa sérios impactos ambientais, além de influenciar, em geral, a baixa qualidade das vias pavimentadas, motivando pesquisas por novos produtos (viáveis e sustentáveis). Nesse sentido, mostram-se promissores materiais como o Agregado Sintético de Argila Calcinada (ASAC), a ser empregado como agregado graúdo. A literatura especializada encerra diversos estudos que apontam sua viabilidade técnica [르 a $\underline{7}$ ] e econômica para uso na massa asfáltica. SILVA e FROTA [ㅁ] assinalam ser viável a produção em larga escala do ASAC, com potencial para atender toda demanda por agregado graúdo na região amazônica, inclusive a demanda reprimida.

Dentre diversos estudos comparativos já realizados com o ASAC, destaca-se a dissertação de mestrado de SILVA [7], que obteve o módulo dinâmico uniaxial (tração com tensão controlada e tração/compressão com deformação controlada) de uma mistura com o agregado alternativo e de outras com agregado convencional (seixo rolado), apontando que os módulos dinâmicos das misturas com ASAC apresentaram-se superiores aos das misturas com seixo para altas temperaturas de ensaio e baixas frequências de aplicação de carga, mostrando que as mesmas, nessas condições que melhor retratam a situação dos pavimentos locais, estão menos susceptíveis às deformações permanentes, como afundamentos de trilhas de roda. Para baixas temperaturas e altas frequências, o processo se inverteu e as misturas com seixo passaram a apresentar maiores valores de $\left|E^{*}\right|$ que as misturas com ASAC. Ou seja, as misturas com o material alternativo mostraram-se menos suscetíveis às variações de temperatura que as misturas com seixo rolado.

O ligante também participa dessa camada superficial dos pavimentos. Suas características viscoelásticas devem ser consideradas, porquanto sua consistência e deformação são variáveis em função da temperatura e do tempo de aplicação da carga, de sorte que, a altas temperaturas, apresenta-se como fluido viscoso e, a baixas temperaturas, a parcela de influência viscosa diminui, a ponto de se evidenciar como sólido elástico para cargas aplicadas em curtos intervalos de tempo [9]. Portanto, é necessário compatibilizar sua característica viscosa, no que se refere à temperatura de serviço.

Em geral, as normas técnicas indicam temperatura em torno de $25^{\circ} \mathrm{C}$ no estudo do desempenho mecânico dos compósitos asfálticos. Exceções fazem-se presentes, como a ASTM D 3497, que norteia a realização dos ensaios de módulo dinâmico a temperaturas de $5,25^{\circ} \mathrm{C}$ e, notadamente, a $40^{\circ} \mathrm{C}$. A incompatibilidade da maioria dessas normas, indicativo à temperatura de ensaio, denota-se, sobretudo, notória nas condições ambientais da maior parte do Brasil, incluindo toda a região amazônica. No caso específico de Manaus/AM, trabalho desenvolvido por PICANÇO et al. [10] evidencia que, nos meses mais quentes do ano, a temperatura na superfície dos pavimentos asfálticos pode alcançar cerca de $60^{\circ} \mathrm{C}$, com uma média de $47,46^{\circ} \mathrm{C}$ para o caso de revestimentos com Areia Asfalto Usinada a Quente (AAUQ).

À luz desse contexto, estuda-se no trabalho em pauta o desempenho mecânico de misturas asfálticas com ASAC (agregado graúdo), considerando-se suas características viscoelásticas. Compara-se o comportamento do ligante quando submetido ao aumento da temperatura compatível com as condições locais, determinando-se o módulo complexo mediante ensaios de rigidez (vigotas) por flexão a quatro pontos, avaliandose também a viabilidade de confecção das vigotas em um molde metálico. Nessa ocasião, também se realiza um paralelo entre os módulos dinâmicos ora determinados com os apresentados em outros trabalhos publicados na literatura especializada.

\section{MATERIAIS E MÉTODOS}

Prosseguindo-se com as pesquisas desenvolvidas pelo Grupo de Geotecnia (GEOTEC) da Universidade Federal do Amazonas (UFAM), utilizou-se como agregado graúdo o Agregado Sinterizado de Argila Calcinada (ASAC) em substituição à brita, por conta dos promissores resultados com esse material alternativo e do seu potencial para largo emprego nas obras viárias locais. Igualmente, empregou-se o CAP 50-70, por constituirse no ligante tradicionalmente aplicado nas obras viárias regionais, investigando-se seu desempenho a temperaturas mais elevadas e condizentes com as condições locais. Participou ainda do compósito asfáltico areia (agregado miúdo) obtida no mercado local e o cimento portland (material de enchimento ou fíler mineral).

Quanto à dosagem mineral, seguiu-se a metodologia Superpave, resultante do programa SHRP, que estabelece uma faixa granulométrica limitada segundo pontos de controle, os quais são função do Tamanho Máximo Nominal do agregado [11, 12]. A determinação do teor de ligante acompanhou a citada metodologia, cuja principal inovação consiste no modo de compactação com uso do Compactador Giratório Superpave (CGS).

A obtenção do teor de projeto, por meio da metodologia Superpave, pode ser resumida no seguinte roteiro: a) selecionam-se três misturas com diferentes granulométricas; b) estimam-se teores de ligantes (asfalto) iniciais; c) compactam-se dois CPs para cada composição com um inicial teor de asfalto (ASTM D 6925); d) moldam-se duas amostras para cada mistura e calcula-se a $G_{m m}$ (ASTM D 2041); e) determina-se a $G_{m b}$ 
dos CPs compactados (ASTM D 1188 ou ASTM D 2726, caso participe material absorsivo); f) calculam-se e avaliam-se os parâmetros dos CPs compactados $\left(\% \mathrm{G}_{\mathrm{mm}}\right.$ a $\mathrm{N}_{\mathrm{ini}}, \% \mathrm{G}_{\mathrm{mm}}$ a $\mathrm{N}_{\text {des }}$ ou $\mathrm{V}_{\mathrm{v}}, \% \mathrm{G}_{\mathrm{mm}}$ a $\mathrm{N}_{\max }, \mathrm{VAM}$, RBV e P/A). Provavelmente nesta etapa inicial nenhum compósito atenderá a todos os requisitos simultaneamente; g) com base nos valores calculados, estimam-se novos teores de ligante para $\% \mathrm{G}_{\mathrm{mm}}$ a $\mathrm{N}_{\mathrm{des}}$, sendo determinados os demais parâmetros. Se nenhuma for aprovada em todos os requisitos, reavaliam-se as misturas granulométricas e reinicia-se o mencionado procedimento; h) seleciona-se a mistura que indique maior folga referente aos parâmetros estimados e prosseguem-se os ensaios; i) para a mistura granulométrica elegida, compactam-se dois CPs alusivo a cada um dos seguintes teores de ligante: estimado, estimado $\pm 0,5 \% \mathrm{e}$ estimado $+1,0 \%$; j) moldam-se duas amostras da composição com teor de asfalto estimado e determina-se a $G_{m m}$; h) calcula-se a $G_{m m}$ para as demais misturas pela sua relação com $G_{s e}$ e teor de ligante; l) determina-se a $\mathrm{G}_{\mathrm{mb}}$ dos CPs compactados; $\left.\mathrm{m}\right)$ calculam-se e avaliam-se os parâmetros dos CPs compactados $\left(\% \mathrm{G}_{\mathrm{mm}}\right.$ a $\mathrm{N}_{\mathrm{ini}}, \% \mathrm{G}_{\mathrm{mm}}$ a $\mathrm{N}_{\text {des }}$ ou $\mathrm{V}_{\mathrm{v}}, \% \mathrm{G}_{\mathrm{mm}}$ a $\mathrm{N}_{\max }, \mathrm{VAM}, \mathrm{RBV}$ e P/A); n) geram-se gráficos relativos a cada um dos parâmetros em função dos teores de asfalto. Provavelmente o compósito com teor de ligante estimado atenderá aos requisitos. Caso contrário, o teor de projeto correspondente a Vv de $4 \%$ pode ser obtido via gráfico, bem como os demais parâmetros. Por fim, a absorção de asfalto pelo agregado $\left(\mathrm{P}_{\mathrm{ba}}\right)$ pode ser determinado pela equação tradicional que o exprime como uma porcentagem em peso do agregado.

\subsection{Módulo de Rigidez ou Módulo Complexo}

LYTTON [13] aborda as características gerais da rigidez do Concreto Asfáltico. Cita que em compósitos asfálticos, diante de seu comportamento viscoelástico, as deformações decorrentes da aplicação de uma carga são divididas em duas parcelas, uma oriunda da resposta elástica e outra devido à parcela viscosa do material. A primeira se manifesta de forma praticamente instantânea e a segunda é função do tempo de aplicação da carga. Assim, uma forma de se medir a resposta elástica das misturas asfálticas consiste em submeter o corpo de prova a uma carga instantânea e medir a deformação correspondente, ou o contrário, dado uma deformação instantânea, determina-se a carga relacionada. Definem-se, então, os ensaios conhecidos como creep estático axial e ensaio de módulo de relaxação, respectivamente.

Esses ensaios, embora aparentem simplicidade, envolve complicações quanto à aplicação de solicitações instantâneas, que na prática são extremamente difíceis de executar. Alternativamente, concebeu-se a aplicação de pulsos de carga senoidais com o monitoramento dos deslocamentos gerados também senoidais. Em tal experimento determina-se o módulo de rigidez ou módulo complexo, conforme as equações 1 e 2 [14].

$$
\begin{aligned}
& \sigma(t)=\sigma_{0} e^{i \omega t} \\
& \varepsilon(t)=\varepsilon_{0} e^{i(\omega t-\varphi)}
\end{aligned}
$$

Sendo $\sigma_{0}$ e $\varepsilon_{0}$, respectivamente, as amplitudes de tensão e deformação, $\omega$ a frequência de aplicação de carga e $\varphi$ o ângulo de fase. Este consiste na diferença de tempo entre os picos de tensão e deformação.

A relação entre a tensão senoidal e a deformação define o módulo complexo (equação 3).

$$
E^{*}=\frac{\sigma(t)}{\varepsilon(t)}=\frac{\sigma_{0}}{\varepsilon_{0}} e^{i \varphi}=\frac{\sigma_{0}}{\varepsilon_{0}}[\cos \varphi+i \cdot \operatorname{sen} \varphi]=E^{\prime}+i E^{\prime \prime}
$$

Os parâmetros E' e E” são, respectivamente, a parte real e imaginária do módulo complexo, conhecidas como storage modulus (módulo elástico) e loss modulus (módulo viscoso).

O quociente entre a amplitude da tensão e a amplitude da deformação (equação 4) é definido como módulo dinâmico $\left|E^{*}\right|$ e representa o valor absoluto do módulo complexo $E^{*}$, que pode ser concebido graficamente em um plano complexo conforme a Figura 1.

$$
\left|E^{*}\right|=\frac{\sigma_{0}}{\varepsilon_{0}}=\left|\sqrt{\left(E^{\prime}\right)^{2}+\left(E^{\prime \prime}\right)^{2}}\right|
$$




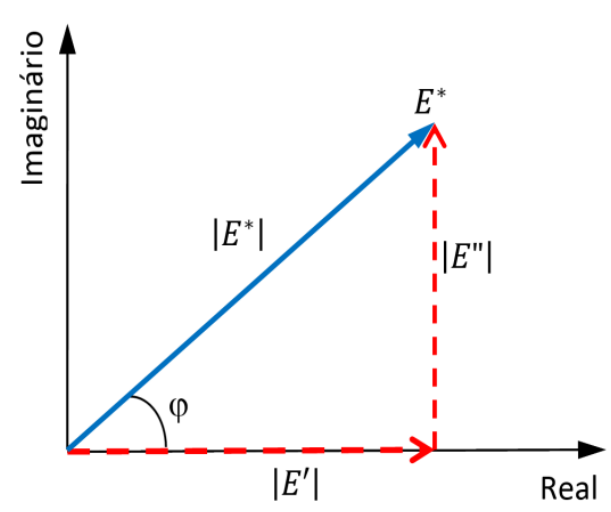

Figura 1: Esquema de solicitação e resposta no ensaio de módulo complexo.

Com o módulo dinâmico e o ângulo de fase obtém-se o storage e loss modulus pelas equações 5 e 6. Matematicamente, $\sigma_{0}$ representa a tensão dinâmica máxima e $\varepsilon_{0}$ indica a deformação axial recuperável máxima.

$$
\begin{aligned}
& E^{\prime}=\left|E^{*}\right| \cos \varphi \\
& E^{\prime \prime}=\left|E^{*}\right| \operatorname{sen} \varphi
\end{aligned}
$$

$E^{\prime}$ constitui a parcela real do módulo complexo (elástica do material), $E^{\prime \prime}$ parcela imaginária desse parâmetro (parte viscosa) e o ângulo de fase $\varphi$ que indica o atraso de $\varepsilon_{0}$ em relação à $\sigma_{0}$, sendo matematicamente expresso pela equação 7. Trata-se de um indicador das propriedades viscosas. Para um material puramente elástico ou puramente viscoso, mostra valores iguais a $\varphi=0^{\circ}$ ou $\varphi=90^{\circ}$, respectivamente.

$$
\varphi=\frac{t_{i}}{t_{p}} \times 360
$$

Sendo:

$t_{i}=$ fração de tempo entre os picos de tensão e deformação;

$t_{p}=$ tempo de um ciclo de carga.

O módulo dinâmico e o ângulo de fase, embora sejam parâmetros do material, variam com a frequência de aplicação de carga, assim como referente à temperatura. No caso dos pavimentos asfálticos, a frequência está relacionada à velocidade dos veículos e a temperatura dependente das condições ambientais. Portanto, os ensaios devem ser realizados procurando-se representar as condições dos pavimentos em campo.

\subsection{Ensaios de Flexão a quatro pontos}

O ensaio de flexão a quatro pontos consiste de uma viga prismática com quatro apoios. Dois pontos são internos, localizados a um terço dos extremos, utilizados para aplicação da carga. Os outros dois apoios situamse nas extremidades, do tipo articulado, permitindo que girem sem permitirem deslocamento na direção da carga aplicada. Essa forma estrutural impõe que o vão central da viga fique submetido a uma flexão pura, o que o aproxima das premissas admitidas para desenvolvimento das equações gerais da viga [15, 20], que consideram a ocorrência de flexão pura. Igualmente, as deformações no centro da viga ficam livres de efeitos decorrentes de pontos de concentração de tensões, posto que as cargas encontram-se concentradas nos terços médios. Em suma, esse arranjo experimental em quatro pontos diminui as incertezas e propagação dos erros e reduz a dispersão dos resultados.

Partindo-se da fórmula de flexão e da equação da linha elástica de vigas, deduziu-se as equações que fornecem a tensão nas fibras externas e a deflexão para o caso particular desse carregamento. Fazendo-se $\mathrm{a}=\mathrm{L} / 3$ e $\mathrm{x}=\mathrm{L} / 2$, as equações que fornecem a tensão, módulo de rigidez e deformação específica no centro do vão da viga são as seguintes (Equações 8, 9 e 10): 


$$
\begin{aligned}
& \sigma=\frac{P L}{b h^{2}} \\
& E_{s}=\frac{23 P L^{3}}{108 b h^{3} \Delta} \\
& \epsilon_{t}=\frac{\sigma}{E_{s}}=\frac{108 h \Delta}{23 L^{2}}
\end{aligned}
$$

Tendo-se:

$\sigma=$ tensão normal;

$E_{s}=$ módulo de elasticidade;

$\Delta=$ deflexão da viga;

$P=$ carga;

$L=$ comprimento;

$b=$ largura da viga (base);

$h=$ altura da viga;

$\varepsilon_{t}=$ deformação específica.

O ensaio é especificado pela norma EN 12697-26, que consiste na aplicação de uma carga sinusoidal no corpo de prova prismático, medindo-se a carga aplicada e a deflexão correspondente. A fim de obter dados que melhor representem as condições ambientais das regiões tropicais, foram consideradas temperaturas a partir de $25^{\circ} \mathrm{C}$, aumentando-se gradualmente em $5^{\circ} \mathrm{C}$ até alcançar o valor de $55^{\circ} \mathrm{C}$.

Com relação às frequências de aplicação de cargas, de modo a simular as ações geradas pelo tráfego na base das camadas betuminosas do pavimento, utilizou-se a série de $1 \mathrm{~Hz}, 3 \mathrm{~Hz}, 10 \mathrm{~Hz}, 20 \mathrm{~Hz}$ e $1 \mathrm{~Hz}$. A repetição da primeira frequência tem a finalidade de verificar se o corpo de prova foi danificado ao longo do experimento. Caso a diferença dos módulos entre a primeira e última medição para a mesma temperatura seja superior a $3 \%$, considera-se danificado a amostra.

Quanto ao modo de carregamento, optou-se pela deformação controlada, com amplitude máxima de deformação de $50 \mu \mathrm{m} / \mathrm{m}$, valor que, segundo a norma, não causa danos ao corpo de prova, pois, como já mencionado, necessita-se preservar as amostras para a sequência de ensaios.

Para confecção dos corpos de prova concebeu-se um molde metálico com rigidez suficiente para permitir compactação da massa asfáltica sem ocorrência de deformação, garantindo-se as dimensões dentro dos limites de tolerância da norma. O molde foi fabricado de modo a permitir total desmontagem para facilitar a retirada do corpo de prova, sendo composto de uma base sob a qual são fixadas as peças laterais. A parte superior consistiu-se de uma peça metálica rígida que se encaixava no interior do molde, sobre a qual era aplicado esforço para fins de compactação de acordo com parâmetros estabelecidos no procedimento de dosagem de seus componentes.

Na realização dos ensaios mecânicos empregou-se o aparelho de flexão de quatro pontos da IPC Global (Four Point Bending Apparatus), constituído de um sistema pneumático para transmissão da força aos dois apoios internos, transdutores para aquisição de dados e unidade de controle interligada a um computador pessoal que permite a configuração e registro dos dados adquiridos. Além disso, dispõem-se de uma câmara climática capaz de variar a temperatura (Figura 2). 
a)
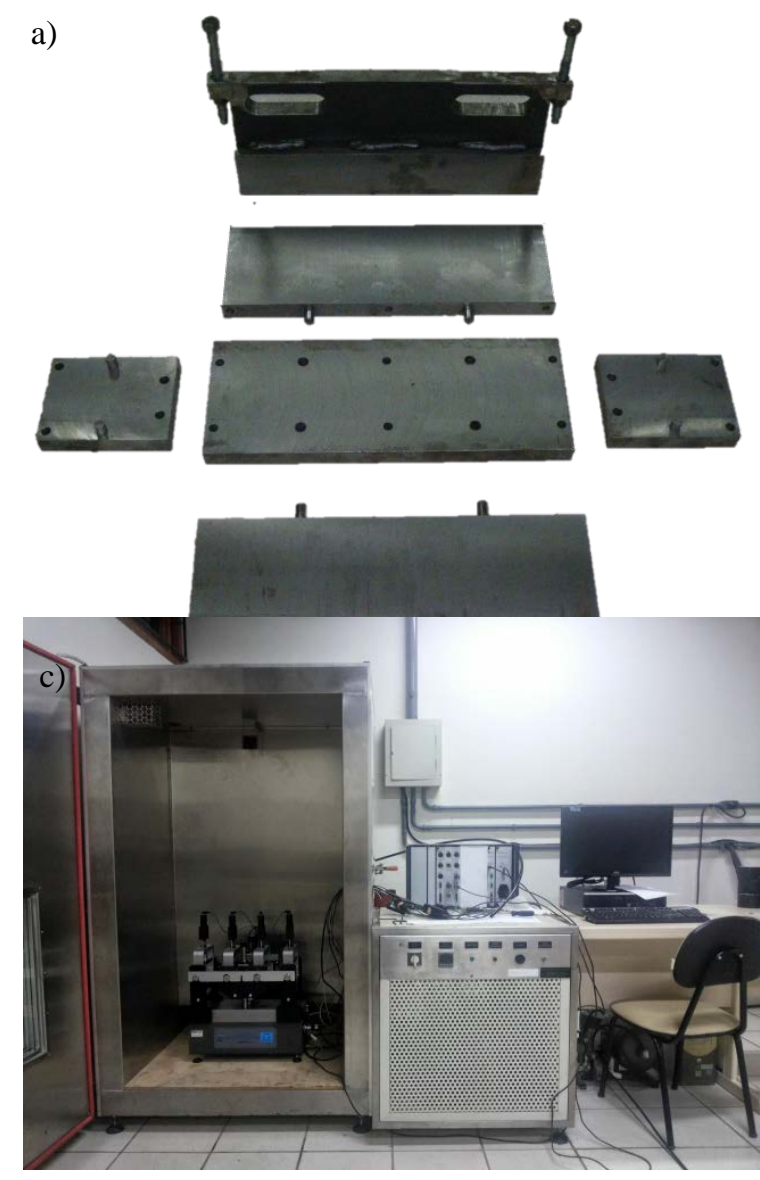

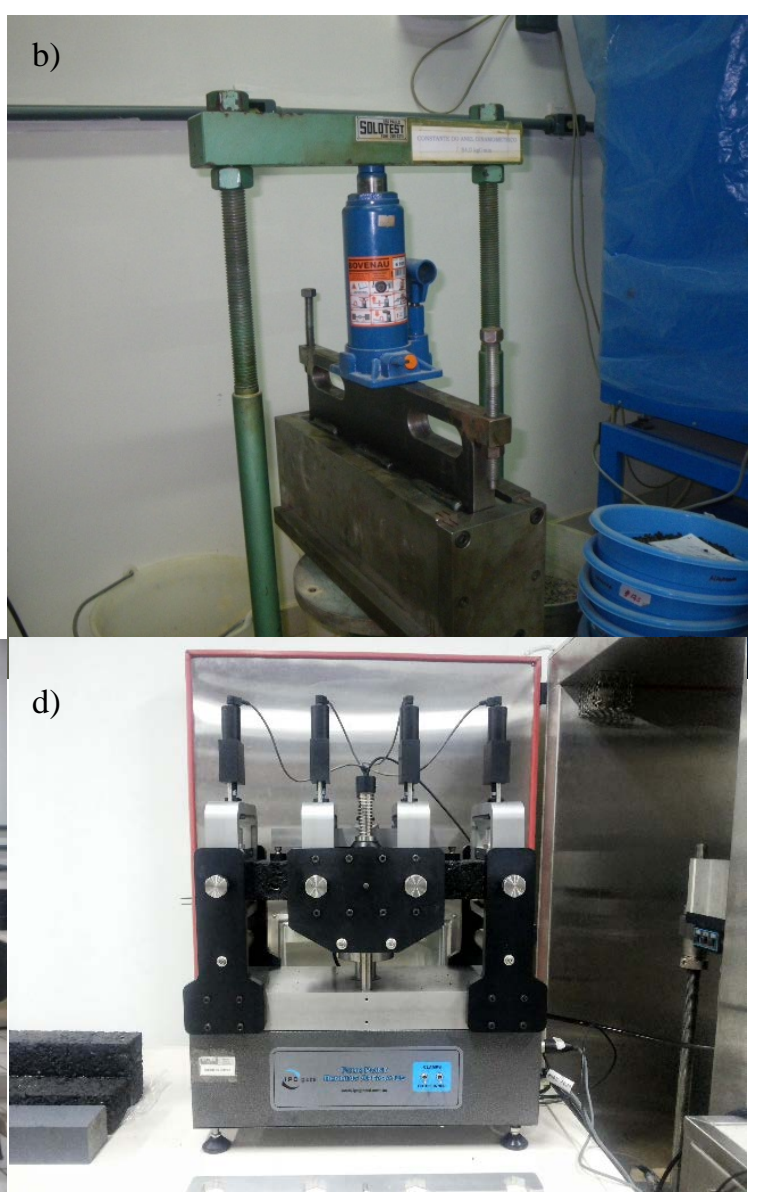

Figura 2: Equipamentos utilizados para realização dos ensaios mecânicos. Molde utilizado pata moldagem (a), sistema de compactação (b); visão geral da prensa, incluindo a câmara climatizada (c) e aparelho de flexão de quatro pontos (d).

\section{RESULTADOS}

\subsection{Caracterização dos Agregados, Dosagem das Misturas e Moldagem dos Corpos de Prova}

Os agregados apresentaram as características físicas dispostas na Tabela 1 e Figura 3. Para atendimento da norma no tocante à confecção dos corpos de prova, necessitou-se limitar o tamanho máximo do agregado graúdo, mediante fracionamento da distribuição granulométrica do ASAC, obtendo-se uma nova graduação designada de ASAC fracionado. Encontram-se na Tabela 2 os dados concernentes à dosagem mineral obtida por meio da metodologia Superpave.

Tabela 1: Caracterização física dos agregados: densidade aparente (Gsb), densidade aparente na condição superfície

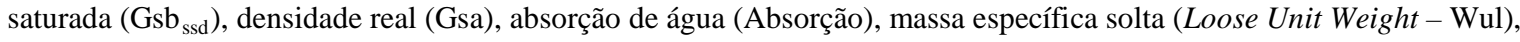
massa específica compactada (Rodded Unit Weight - Wur), adesividade ao ligante asfáltico (Adesividade).

\begin{tabular}{l|l|l}
\hline \multirow{2}{*}{ ANÁLISE } & \multicolumn{2}{c}{ AMOSTRA } \\
\cline { 2 - 3 } & \multicolumn{1}{|c}{ ASAC SUC } & AREIA MAO \\
\hline $\mathrm{Gsb}\left(\mathrm{g} / \mathrm{cm}^{3}\right)$ & 1,855 & 2,632 \\
\hline $\mathrm{Gsb}_{\text {ssd }}\left(\mathrm{g} / \mathrm{cm}^{3}\right)$ & 2,133 & \\
\hline $\mathrm{Gsa}\left(\mathrm{g} / \mathrm{cm}^{3}\right)$ & 2,571 & 2,692 \\
\hline Absorção $(\%)$ & 15 & 0 \\
\hline Wul $\left(\mathrm{kg} / \mathrm{m}^{3}\right)$ & 1062 & \\
\hline Wur $\left(\mathrm{kg} / \mathrm{m}^{3}\right)$ & 1126,35 & 1676 \\
\hline Adesividade & Satisfatória & \\
\hline
\end{tabular}




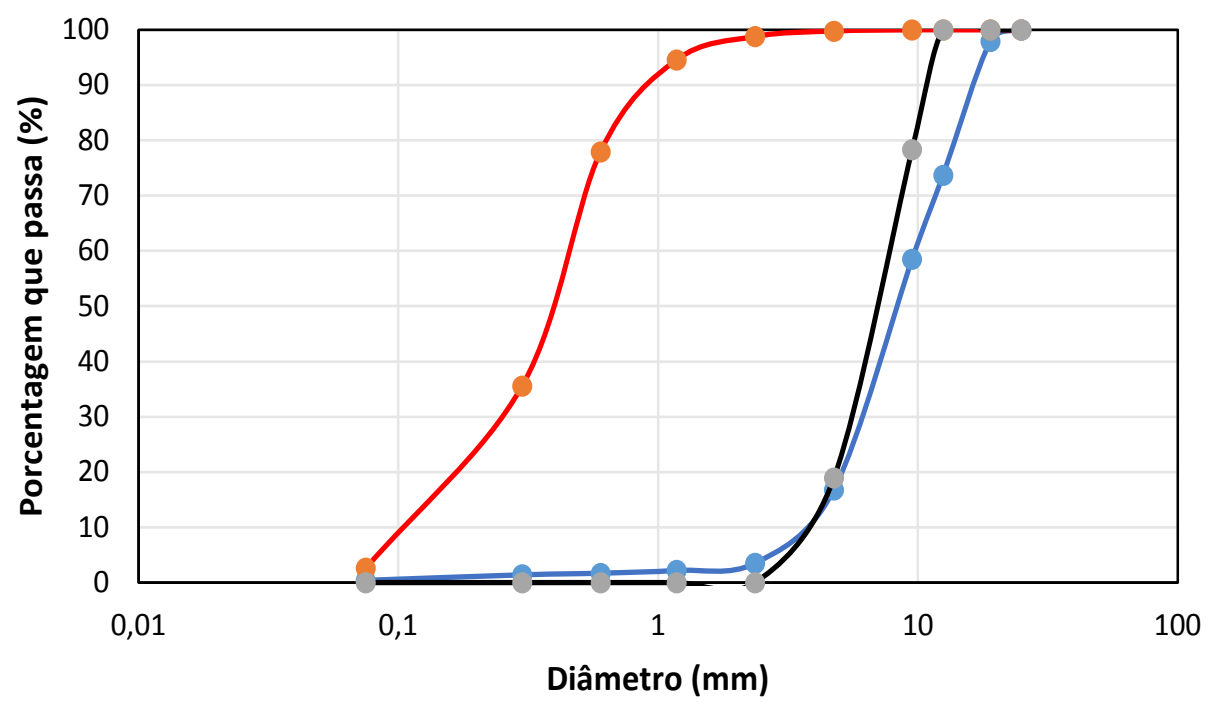

$\longrightarrow$-ASAC $\quad \longrightarrow$ Areia MAO $\quad-$ ASAC fracionado

Figura 3: Curva granulométrica dos agregados.

Tabela 2: Proporção das misturas minerais para estudo de dosagem.

\begin{tabular}{l|l|l|l}
\hline \multicolumn{1}{c|}{ COMPONENTES } & \multicolumn{1}{|c|}{ MISTURA 1 } & MISTURA 2 & MISTURA 3 \\
\hline ASAC Fracionado & 53,66 & 62,00 & 50,00 \\
\hline Areia MAO & 42,44 & 34,00 & 45,00 \\
\hline Cimento Portland & 3,90 & 4,00 & 5,00 \\
\hline
\end{tabular}

Para obtenção do teor de projeto seguiu-se o roteiro apresentado no início da seção 2, realizando-se, para cada mistura, duas compactações no CGS. Adotaram-se os teores de ligante de 10,6\%, 11,4\% e 9,6\%, respectivamente às misturas 1 , 2 e 3 . Observou-se, de início, que nenhuma das composições atendeu à premissa básica de $96 \%$ de compactação em relação à $\mathrm{G}_{\mathrm{mm}}$, bem como referente a outros parâmetros. Deste modo, com base nesses resultados iniciais, avaliou-se que a mistura 2, reduzindo-se seu teor de ligante inicial, poderia atender a todos os requisitos. Dessa forma, a mesma foi selecionada para novas tentativas, compondo-se com teores de ligante de 9,9\%, 10,4\%, 10,9\% e 11,4\%. Nessa nova rodada de ensaios, notou-se que a mistura 2 com 10,9\% de material asfáltico mostrou aprovação em todos os critérios, sendo este, portanto, o teor “ótimo” de ligante (Tabela 3).

Tabela 3: Avaliação dos parâmetros nos teores de ligante iniciais.

\begin{tabular}{|c|c|c|c|c|c|c|c|c|c|}
\hline \multirow{2}{*}{$\begin{array}{l}\text { Teor de } \\
\text { ligante }\end{array}$} & \multicolumn{3}{|c|}{$\mathbf{G}_{\mathrm{MB}}$ corrigido $\left[\% \mathbf{G}_{\mathrm{MM}}\right]$} & \multirow{2}{*}{$\begin{array}{c}\% \text { de } \\
\text { vazios } \\
\left(V_{\mathrm{v}}\right) \\
\end{array}$} & \multirow{2}{*}{ VAM } & \multirow{2}{*}{ RBV } & \multirow{2}{*}{$P \ell_{E}$} & \multirow{2}{*}{$\begin{array}{c}\text { PÓIASFALTO } \\
\text { EFETIVO } \\
\text { (PIA) } \\
\end{array}$} & \multirow{2}{*}{ AVALIAÇÃO } \\
\hline & $\mathbf{N}_{\text {INICIAL }}$ & $\mathbf{N}_{\text {PROJETO }}$ & $\mathbf{N}_{\text {MÁXIMO }}$ & & & & & & \\
\hline 9,9 & 85,0 & 93,7 & 94,7 & 6,3 & 16,7 & 62 & 5,5 & 0,89 & Não atende \\
\hline 10,4 & 86,0 & 94,8 & 95,8 & 5,2 & 16,7 & 68 & 6,0 & 0,81 & Não atende \\
\hline 10,9 & 87,0 & 96,0 & 97,0 & 4,0 & 16,6 & 75 & 6,5 & 0,75 & Atende \\
\hline 11,4 & 88,1 & 97,4 & 98,1 & 2,6 & 16,4 & 83 & 7,1 & 0,69 & Não atende \\
\hline Critérios: & $<=89$ & 96 & $<=98$ & $=4$ & $>=14$ & 65 a 75 & & 0,6 a 1,2 & \\
\hline
\end{tabular}

O procedimento de dosagem pela metodologia Superpave passa por um processo de tentativas em que os valores estimados inicialmente são importantes para maior facilidade na convergência do resultado. Nesse aspecto, a falta de conhecimento do comportamento específico do material alternativo impôs dificuldade adi- 
cional, exigindo maior número de tentativas até definirem-se "valores iniciais" adequados. Isso ocorreu, sobretudo, pela maior absorção de asfalto pelo agregado $\left(\mathrm{P}_{\mathrm{ba}}\right)$, que resultou em $4,89 \%$, valor elevado quando comparado com agregados convencionais, que não costumam ultrapassar $1 \%$, como os apresentados no trabalho de GOUVEIA et al [21], em que agregados de basalto e de gabro apresentaram variações entre $0,04 \%$ e $0,88 \%$. Dessa forma, o valor obtido nesse trabalho já pode ser usado como referência inicial no caso de novas dosagens utilizando-se da mesma metodologia e material alternativo.

Alcançado o teor "ótimo" e a densidade da mistura correspondente à compactação relativo ao número de giros de projeto, calculou-se a quantidade de material necessário para se atingir o mesmo grau de compactação, referente às dimensões dos corpos de prova prismáticos a serem ensaiados à flexão a quatro pontos. Realizada a mistura, verteu-se a massa asfáltica no molde para compactação mediante aplicação de golpes e vibração, obtendo-se 18 (dezoito) corpos de prova prismáticos. Observou-se que as medidas da largura da base e do comprimento mantiveram-se constantes para todas as vigas (corpos de prova), em decorrência da rigidez do molde. Nesse caso, realizou-se o controle da compactação monitorando-se a altura, ou seja, compactou-se a massa asfáltica até se atingir esta dimensão pré-estabelecida. A altura final das vigas oscilou entre $50,2 \mathrm{~mm}$ e $51,9 \mathrm{~mm}$.

\subsection{Caracterização Mecânica}

Como resultado dos ensaios mecânicos, o software que controla o equipamento gerou um relatório com os dados do ensaio para cada corpo de prova e temperatura, incluindo parâmetros de entrada e resultados. Por conseguinte, disponibilizando para cada frequência, a amplitude de força e de deslocamento, o ângulo de fase e o módulo complexo, dentre outras informações.

Além do relatório consolidado, o software produz outros relatórios, para cada frequência configurada, com os dados discretizados de tempo, deslocamentos e carga, sendo possível traçar os gráficos representativos dos pulsos de carga e do correspondente deslocamento, que proporciona subsídios necessárias para cálculo do módulo de rigidez dinâmica e do ângulo de fase. Exemplifica-se na Tabela 4 as linhas iniciais do relatório gerado para um dos corpos de prova submetidos, particularmente a $25^{\circ} \mathrm{C}$ e pulsos de $1 \mathrm{~Hz}$, assim como o gráfico correspondente ilustrado na Figura 4.

Ainda em fase de análise preliminar dos dados, consolidaram-se os resultados para as dezoito vigas, a $25^{\circ} \mathrm{C}$, cujas informações constam na Tabela 5. Repetiu-se o experimento para as dezoito vigas visando analisar a convergência e a confiabilidade dos resultados. Dentre as dezoito vigas, três (1.10, 1.12 e 1.15) apresentaram uma divergência em torno da média (de todas as frequências) superior a $10 \%$, podendo ser consequência da falta de homogeneidade na compactação. Porém, de qualquer forma, a convergência dos resultados mostrou-se satisfatória, podendo-se prosseguir com os testes.

Tabela 4: Últimas linhas do relatório para um corpo de prova submetidos à temperatura de $25^{\circ} \mathrm{C}$ e pulsos de $1 \mathrm{~Hz}$.

\begin{tabular}{l|l|l|l|l}
\hline $\begin{array}{c}\text { CICLO } \\
\#\end{array}$ & \multicolumn{1}{|c|}{$\begin{array}{c}\text { TEMPO } \\
\text { (segundos) }\end{array}$} & \multicolumn{1}{|c|}{$\begin{array}{c}\text { ATUADOR } \\
(\mathbf{m m})\end{array}$} & \multicolumn{1}{|c}{$\begin{array}{c}\text { CARGA } \\
(\mathbf{k N})\end{array}$} & \multicolumn{1}{c}{$\begin{array}{c}\text { ON-SPECIMEN } \\
(\mathbf{m m})\end{array}$} \\
\hline \multirow{2}{*}{100} & 99,964 & 0,064545 & $-0,015656$ & $-0,010437$ \\
\cline { 2 - 5 } & 99,968 & 0,063629 & $-0,016205$ & $-0,010117$ \\
\cline { 2 - 5 } & 99,972 & 0,062866 & $-0,017441$ & $-0,009735$ \\
\cline { 2 - 5 } & 99,976 & 0,062408 & $-0,01799$ & $-0,009308$ \\
\hline & 99,98 & 0,06134 & $-0,019089$ & $-0,008896$ \\
\cline { 2 - 5 } & 99,984 & 0,060577 & $-0,019775$ & $-0,00853$ \\
\cline { 2 - 5 } & 99,988 & 0,059967 & $-0,020462$ & $-0,008148$ \\
\cline { 2 - 5 } & 99,992 & 0,059662 & $-0,020737$ & $-0,00798$ \\
\hline
\end{tabular}




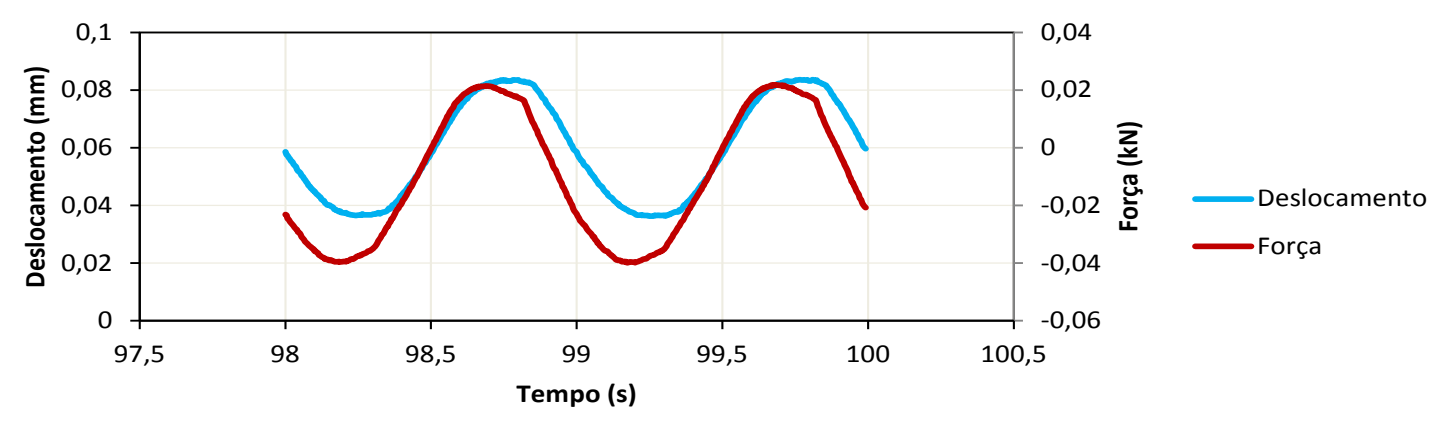

Figura 4: Gráfico gerado para um corpo de prova submetido à temperatura de $25^{\circ} \mathrm{C}$ e pulsos de $1 \mathrm{~Hz}$.

Tabela 5: Módulo de Rigidez Dinâmico (MPa) para os corpos de prova a $25^{\circ} \mathrm{C}$, incluindo média, desvio padrão $(s)$ e coeficiente de variação $(C V)$.

\begin{tabular}{|c|c|c|c|c|c|}
\hline \multirow{2}{*}{ VIGA } & \multicolumn{5}{|c|}{ FREQUÊNCIA (HZ) } \\
\hline & 1 & 3 & 10 & 20 & 1 \\
\hline 1.1 & 1406,0 & 1756,0 & 2147,0 & 2207,0 & 1420,0 \\
\hline 1.2 & 1358,0 & 1679,0 & 2032,0 & 2065,0 & 1364,0 \\
\hline 1.3 & 1353,0 & 1673,0 & 2023,0 & 2053,0 & 1359,0 \\
\hline 1.4 & 1313,0 & 1639,0 & 2000,0 & 2025,0 & 1320,0 \\
\hline 1.5 & 1437,0 & 1778,0 & 2159,0 & 2228,0 & 1440,0 \\
\hline 1.6 & 1299,0 & 1609,0 & 1957,0 & 2004,0 & 1299,0 \\
\hline 1.7 & 1441,0 & 1766,0 & 2129,0 & 2210,0 & 1440,0 \\
\hline 1.8 & 1265,0 & 1557,0 & 1877,0 & 1915,0 & 1278,0 \\
\hline 1.9 & 1286,0 & 1581,0 & 1921,0 & 1967,0 & 1294,0 \\
\hline 1.10 & 1124,0 & 1415,0 & 1746,0 & 1775,0 & 1125,0 \\
\hline 1.11 & 1371,0 & 1697,0 & 2053,0 & 2132,0 & 1388,0 \\
\hline 1.12 & 1444,0 & 1802,0 & 2214,0 & 2305,0 & 1435,0 \\
\hline 1.13 & 1326,0 & 1632,0 & 1966,0 & 2002,0 & 1342,0 \\
\hline 1.14 & 1286,0 & 1578,0 & 1904,0 & 1948,0 & 1284,0 \\
\hline 1.15 & 1132,0 & 1428,0 & 1755,0 & 1795,0 & 1130,0 \\
\hline 1.16 & 1155,0 & 1475,0 & 1836,0 & 1899,0 & 1165,0 \\
\hline 1.17 & 1150,0 & 1485,0 & 1879,0 & 1990,0 & 1149,0 \\
\hline 1.18 & 1235,0 & 1524,0 & 1855,0 & 1903,0 & 1230,0 \\
\hline Média (MPa) & 1298,9 & 1615,2 & 1969,6 & 2023,5 & 1303,4 \\
\hline$s$ (MPa) & 106,1 & 120,0 & 136,7 & 147,6 & 107,2 \\
\hline$C V(\%)$ & 8,2 & 7,4 & 6,9 & 7,3 & 8,2 \\
\hline
\end{tabular}

Na sequência dos ensaios submeteram-se os corpos de prova às demais temperaturas e selecionaramse cinco vigas (corpos de provas), observando-se as que mostravam valores mais próximos da média. A cada grupo de ensaios aumentou-se a temperatura em $5^{\circ} \mathrm{C}$ até se atingir $55^{\circ} \mathrm{C}$. Os dados obtidos para o Módulo de Rigidez Dinâmico, a cada uma das frequências e temperaturas, foram consolidados respeitantes aos valores médios para melhor visualização dos resultados (Tabela 6). Nota-se que o módulo de rigidez dinâmico aumentou com a frequência e diminuiu com o acréscimo de temperatura. $\mathrm{O}$ mesmo comportamento geral observou-se no trabalho desenvolvido por SILVA [7], que usou o mesmo material graúdo (ASAC) do estudo em pauta, embora com metodologia diferente. No presente caso, visualiza-se o gráfico na Figura 5. 
Tabela 6: Módulo de Rigidez Dinâmico (MPa) para as diversas temperaturas e frequências.

\begin{tabular}{l|l|l|l|l}
\hline \multirow{2}{*}{ TEMPERATURA $^{\circ} \mathbf{C}$} & \multicolumn{4}{|c}{ FREQUÊNCIAS (HZ) } \\
\cline { 2 - 5 } & $\mathbf{1}$ & $\mathbf{3}$ & $\mathbf{1 0}$ & $\mathbf{2 0}$ \\
\hline 25 & 1302,0 & 1608,0 & 1953,4 & 1998,2 \\
\hline 30 & 1048,6 & 1312,6 & 1649,8 & 1776,6 \\
\hline 35 & 712,6 & 940,4 & 1211,6 & 1268,2 \\
\hline 40 & 399,6 & 555,4 & 751,8 & 763,4 \\
\hline 45 & 235,4 & 331,4 & 457,4 & 534,0 \\
\hline 50 & 173,6 & 241,8 & 328,6 & 384,6 \\
\hline 55 & 107,0 & 150,2 & 202,0 & 351,6 \\
\hline
\end{tabular}

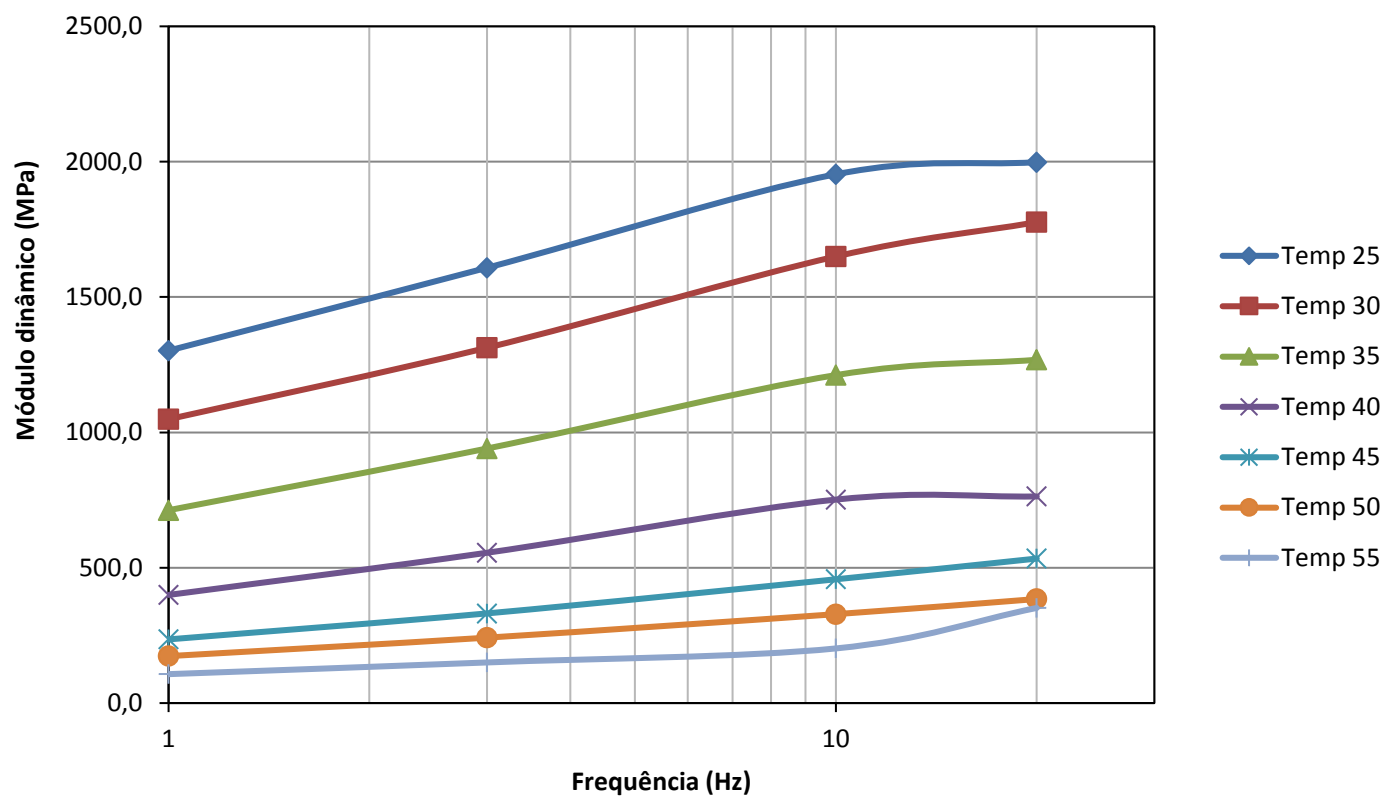

Figura 5: Módulo de rigidez dinâmico.

Na Figura 5, embora as funções apresentem-se como retas até a marca de $10 \mathrm{~Hz}$, nota-se uma mudança do comportamento para a frequência de $20 \mathrm{~Hz}$, à exceção para temperatura $50^{\circ} \mathrm{C}$. Investigando-se mais detalhadamente os resultados, ressalta-se que, embora planejado para uma amplitude de deslocamento constante de $50 \mu \mathrm{m} / \mathrm{m}$, nos casos da frequência igual a $20 \mathrm{~Hz}$, tal deslocamento não foi alcançado nas temperaturas inferiores, e que o erro foi diminuindo à medida que a temperatura cresceu, até atingir o valor estabelecido na temperatura de $55^{\circ} \mathrm{C}$ (Tabela 7). Também consta na Figura 5 uma correlação entre os valores da amplitude e a evolução no padrão dos registros.

Tabela 7: Amplitude dos deslocamentos obtidos, em $\mu \mathrm{m} / \mathrm{m}$.

\begin{tabular}{l|l|l|l|l}
\hline \multirow{2}{*}{ TEMPERATURA $^{\circ} \mathbf{C}$} & \multicolumn{4}{|c}{ FREQUÊNCIAS (HZ) } \\
\cline { 2 - 5 } & \multicolumn{1}{|c}{$\mathbf{1}$} & \multicolumn{1}{|c}{$\mathbf{3}$} & \multicolumn{1}{|c}{$\mathbf{1 0}$} & \multicolumn{1}{c}{$\mathbf{2 0}$} \\
\hline 25 & 51,4 & 51,6 & 47,8 & 19,0 \\
\hline 30 & 49,2 & 49,6 & 49,6 & 30,4 \\
\hline 35 & 49,0 & 48,2 & 51,0 & 31,0 \\
\hline 40 & 48,4 & 47,4 & 50,0 & 37,8 \\
\hline 45 & 48,0 & 47,2 & 49,6 & 42,6 \\
\hline 50 & 48,6 & 48,8 & 49,4 & 45,0 \\
\hline 55 & 48,2 & 48,2 & 49,2 & 50,2 \\
\hline
\end{tabular}


A mudança de comportamento no módulo de rigidez dinâmico para a frequência de $20 \mathrm{~Hz}$, coincide com os deslocamentos que não atingiram o limite estabelecido, sugerindo que o valor do $\left|E^{*}\right|$ igualmente pode variar com a amplitude de deslocamento. Os dados presentes na dissertação de mestrado de BARBOSA [22], alusivos ao desempenho de misturas betuminosas temperadas com ensaios de flexão em quatro pontos, também apontam para variação com a amplitude do deslocamento.

Na Figura 6 têm-se o módulo de rigidez dinâmico em função da temperatura. Como já era esperado, a temperaturas inferiores e altas frequências, o citado parâmetro indicou os maiores valores. Por outro lado, diminuindo-se a frequência e acrescendo-se a temperatura o módulo cai sensivelmente.

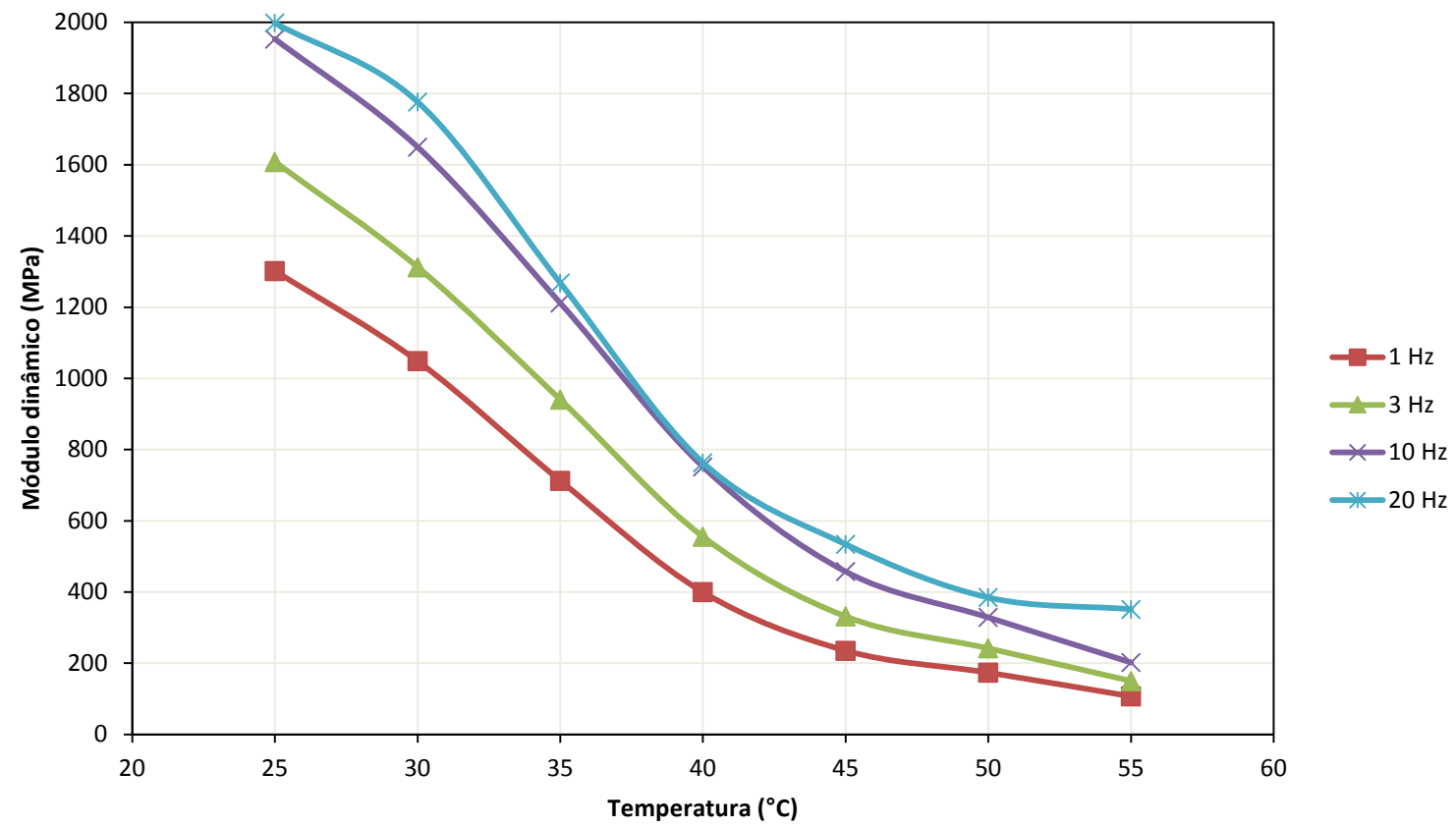

Figura 6: Módulo de rigidez dinâmico em função da temperatura para as diversas frequências.

Em geral na literatura técnica estudam-se as misturas asfálticas em temperaturas em torno de $25^{\circ} \mathrm{C}$, a exemplo do especificado na norma europeia EN 12697-24. Ocorre que nas regiões equatoriais, como na Amazônia, a temperatura média é muito superior a esse valor. Nos meses mais quentes do ano a temperatura média diária na superfície dos pavimentos asfálticos em Manaus (AM) é superior a $40^{\circ} \mathrm{C}$, permanecendo por mais de cinco horas acima de $50^{\circ}[\underline{10}]$. Nessas condições, os resultados dos ensaios demonstraram que o módulo de rigidez da mistura asfáltica é muito pequeno, podendo-se reduzir em 93,3\%, tendo como referência a temperatura de $25^{\circ} \mathrm{C}$, considerando-se também redução da frequência de aplicação de cargas a valores compatíveis com velocidades reais dos veículos.

A fim de situar os presentes resultados, obtidos para um agregado alternativo e a temperaturas mais elevadas que as habituais, frente a valores adquiridos quando utilizados agregados e temperaturas convencionais, selecionaram-se resultados apresentados nas dissertações de SILVA [7] e SHINOHARA [23] e na tese de BARRA [24]. O primeiro, além de realizar trabalho com o mesmo agregado convencional, também o fez para o seixo rolado, alternativa regional ante a escassez de material pétreo, bem como se utilizou de tração/compressão uniaxial para obtenção dos módulos dinâmicos, e os demais utilizaram-se de agregados provenientes de rochas ígneas e a metodologia de flexão a dois pontos, com corpos de prova trapezoidais. Também há diferença nos métodos de dosagem, porém todos se utilizaram do mesmo ligante, CAP 50/70. Além disso, mantendo o foco da presente pesquisa, selecionaram-se somente os resultados para temperaturas superiores a $10^{\circ} \mathrm{C}$ e frequências de $1 \mathrm{~Hz}$ e $3 \mathrm{~Hz}$. Os resultados apresentam-se nos gráficos das Figuras 7 e 8. 


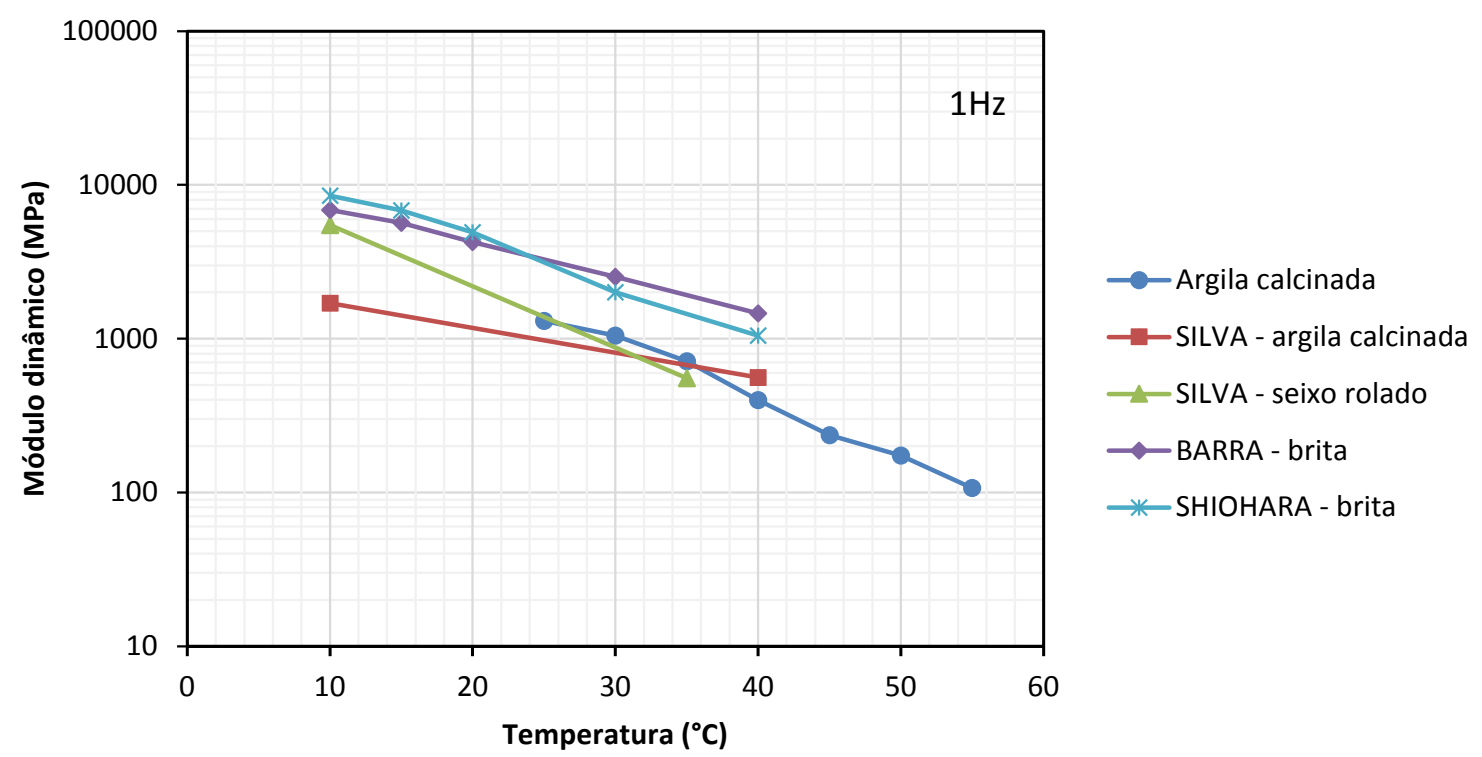

Figura 7: Comparativo entre o desempenho das misturas com argila calcinada e com outros materiais obtidos na literatura especializada para frequência de carregamento de $1 \mathrm{~Hz}$.

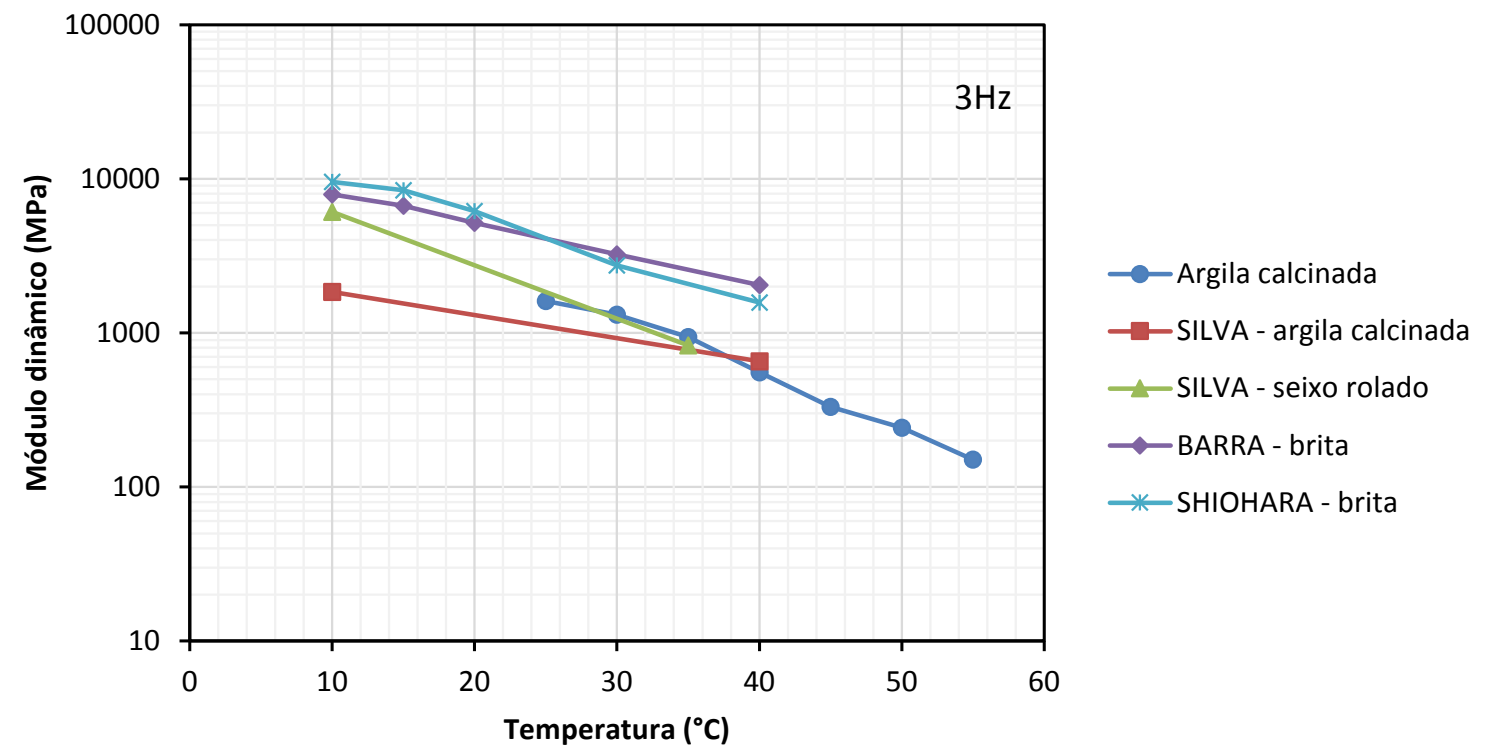

Figura 8: Comparativo entre o desempenho das misturas com argila calcinada e com outros materiais obtidos na literatura especializada para frequência de carregamento de $3 \mathrm{~Hz}$.

Nos gráficos das Figuras 7 e 8 observa-se que na faixa de temperaturas tradicionais o módulo dinâmico do material aqui pesquisado mante-se no mesmo patamar que os obtidos por SILVA [7], que demonstrou haver menor sensibilidade ao aumento de temperatura das misturas com argila calcinada frente às de seixo rolado, evidenciado pela menor inclinação das retas vermelhas comparativamente às verdes. Em relação às britas [23, 24], fica claro que o material alternativo apresenta valor inferior para temperaturas de até $40^{\circ} \mathrm{C}$, no entanto ainda são necessários outros estudos considerando-se o material tradicional a temperaturas mais elevadas para permitir melhor comparação nesta faixa térmica.

Para se ter ideia da ordem de grandeza alusiva à velocidade correspondente à frequência de aplicação dos pulsos de carga, pode-se recorrer ao ábaco publicado por After Barksdale, constante do trabalho de HUANG [25] (Figura 9), que correlaciona velocidade com tempo de aplicação da carga, e à relação empírica estabelecida por Van Der Poel, também apresentada por HUANG [25], dada pela equação 11. 


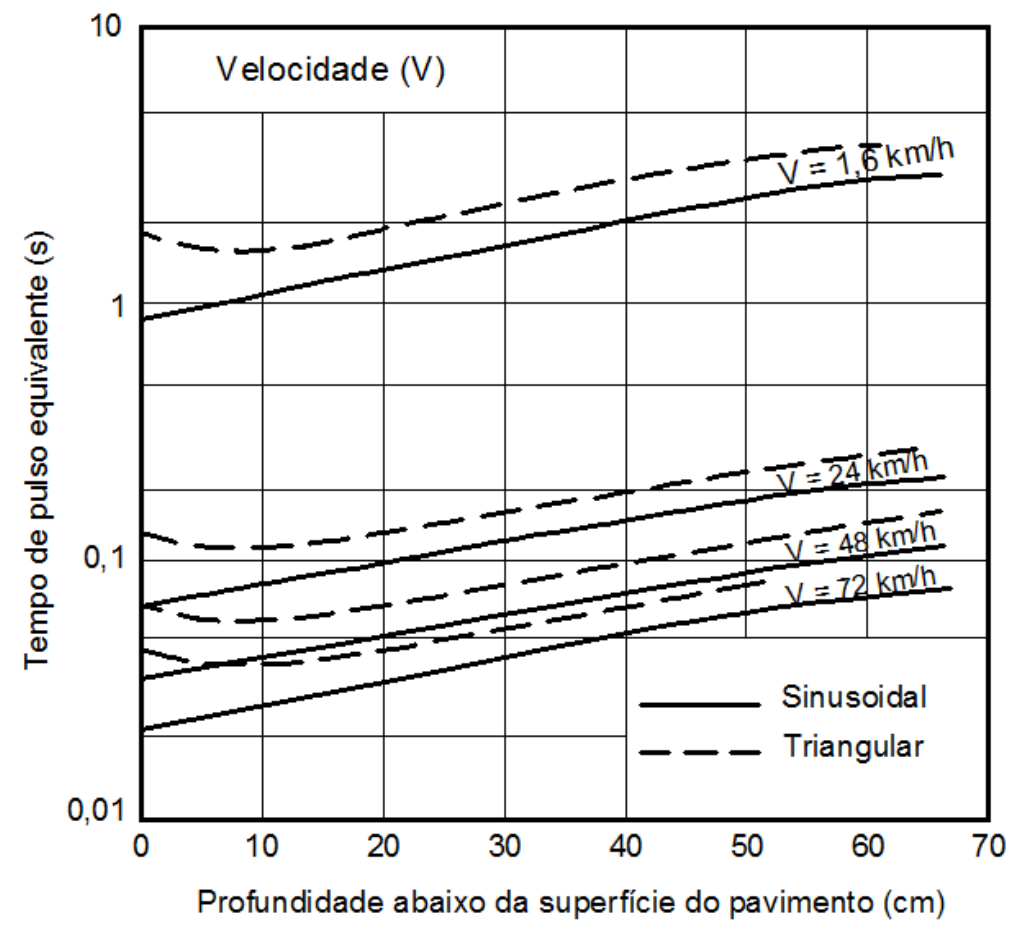

Figura 9: Tempo de pulso de carga equivalente, função da velocidade do veículo e profundidade. Fonte: HUANG [25].

$$
t=\frac{1}{2 \pi f}
$$

sendo:

t- tempo do pulso;

$f$ - frequência.

Com essas ferramentas, verifica-se que a frequência de $1 \mathrm{~Hz}$ equivale a cerca de $20 \mathrm{~km} / \mathrm{h}$, velocidade comum para trânsitos congestionados, e a frequência de $3 \mathrm{~Hz}$ aproxima-se de $40 \mathrm{~km} / \mathrm{h}$, valor bem representativo do transito em vias urbanas.

Assim, considerando-se as condições locais de temperatura e tráfego, o módulo de rigidez dinâmico diário mostrou variação de $1.608 \mathrm{MPa}\left(25^{\circ} \mathrm{C}, 3 \mathrm{~Hz}\right)$ para $107 \mathrm{MPa}\left(55^{\circ} \mathrm{C}, 1 \mathrm{~Hz}\right)$, que corresponde a uma queda de 93,3\%. Aliado ao problema da carência de material pétreo, explica-se, portanto, a grande ocorrência de deformação permanente nos revestimentos asfálticos de Manaus.

Outro importante parâmetro, o ângulo de fase, foi obtido dos ensaios diretamente dos relatórios finais dos testes. Na Tabela 8 encontram-se os dados brutos consolidados, após serem apresentados pelo software que controla os ensaios.

Tabela 8: Ângulos de fase $\left({ }^{\circ} \mathrm{C}\right)$ oriundos dos relatórios, referentes aos valores médios.

\begin{tabular}{l|l|l|l|l}
\hline \multirow{2}{*}{ TEMPERATURA $^{\circ} \mathbf{C}$} & \multicolumn{4}{|c}{ FREQUÊNCIAS (HZ) } \\
\cline { 2 - 5 } & \multicolumn{1}{|c|}{$\mathbf{1}$} & \multicolumn{1}{|c}{$\mathbf{3}$} & $\mathbf{1 0}$ & \multicolumn{1}{c}{$\mathbf{2 0}$} \\
\hline 25 & 19,3 & 17,3 & 15,2 & 14,7 \\
\hline 30 & 22,7 & 17,4 & 14,6 & 17,3 \\
\hline 35 & 26,3 & 24,5 & 22,5 & 27,2 \\
\hline 40 & 31,8 & 30,7 & 29,7 & 39,2 \\
\hline 45 & 34,9 & 35,2 & 36,4 & 58,9 \\
\hline 50 & 35,3 & 36,8 & 40,8 & 71,8 \\
\hline 55 & 36,1 & 39,7 & 48,8 & 84,0 \\
\hline
\end{tabular}


Segundo a análise dos dados apresentadas no início dessa seção, observou-se que para temperaturas superiores a $40^{\circ} \mathrm{C}$ os pulsos de carga exibiam uma variação em torno da função senoidal, e que para os casos de frequência de $20 \mathrm{~Hz}$ não indicaram uma definida forma. Para refinar os resultados, os dados foram submetidos a processo de regressão visando determinar os parâmetros de uma função senóide que melhor se ajustava a cada conjunto de dados. A título ilustrativo dos resultados do ajuste, visualizam-se nas Figuras 10 e 11 os gráficos das funções originadas como resultado dos processos de regressão, tanto da força como do deslocamento, sobre os gráficos gerados com os dados obtidos diretamente dos ensaios. Posterior ao ajuste de todas as curvas calcularam-se os ângulos de fase a partir dos parâmetros determinados com as funções, originando os dados consolidados da Tabela 9.

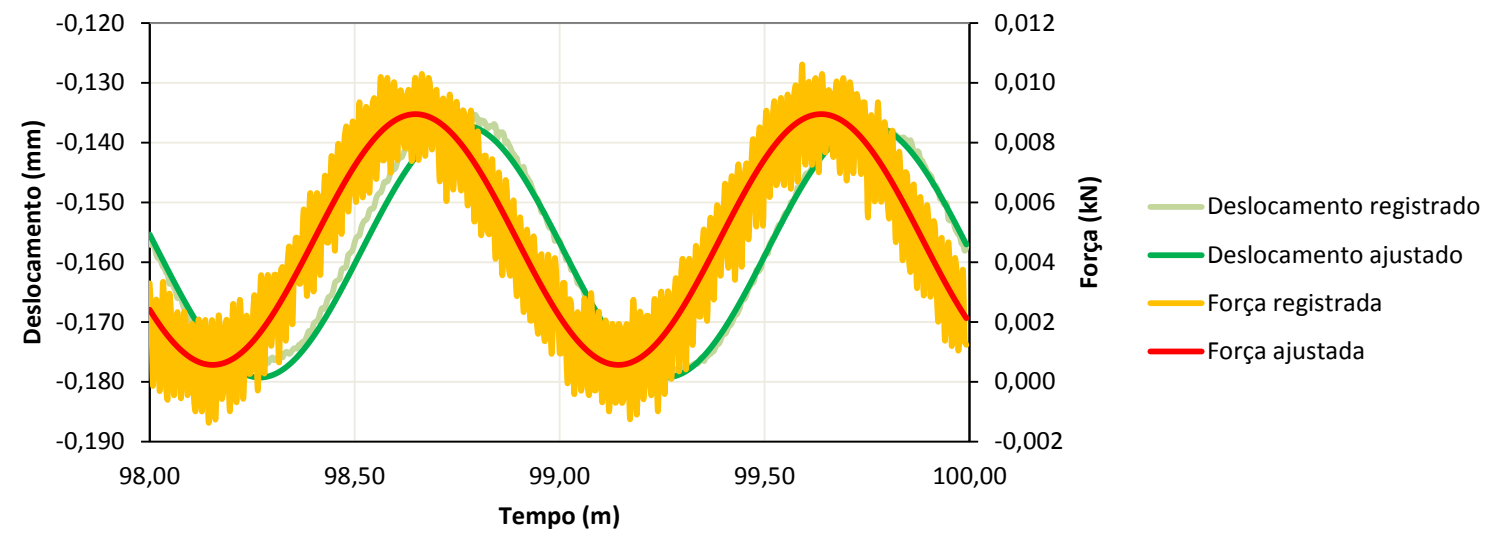

Figura 10: Pulsos de carga e deslocamento $\left(50^{\circ} \mathrm{C}\right.$ e $\left.1 \mathrm{~Hz}\right)$. Resultados dos ajustes sobre os dados originais do ensaio.

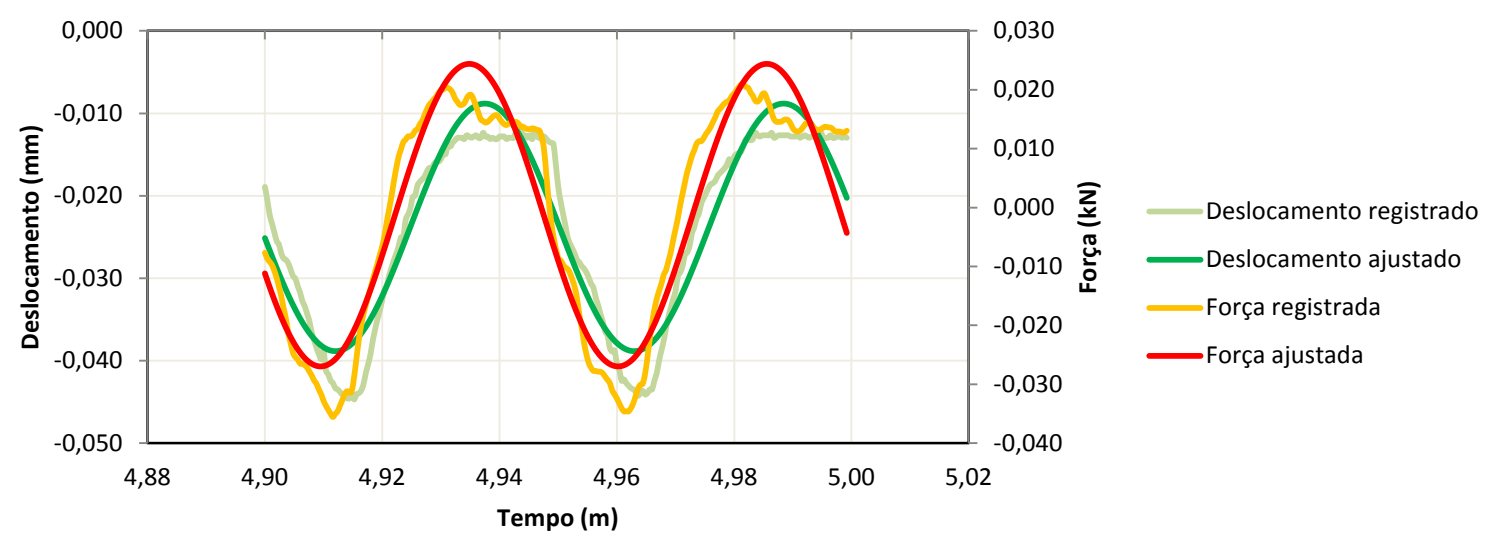

Figura 11: Pulsos de carga e deslocamento $\left(30^{\circ} \mathrm{C}\right.$ e $\left.20 \mathrm{~Hz}\right)$. Resultados dos ajustes sobre os dados originais do ensaio.

Tabela 9: Ângulos de fase $\left({ }^{\circ} \mathrm{C}\right)$ após ajustes dos dados.

\begin{tabular}{l|l|l|l|l}
\hline \multirow{2}{*}{$\begin{array}{c}\text { TEMPERATURA } \\
\left({ }^{\circ} \mathbf{C}\right)\end{array}$} & \multicolumn{4}{|c}{ FREQUÊNCIA (HZ) } \\
\cline { 2 - 5 } & \multicolumn{1}{|c|}{$\mathbf{3}$} & \multicolumn{1}{c}{$\mathbf{1 0}$} & $\mathbf{2 0}$ \\
\hline 25 & 22,4 & 22,0 & 16,4 & 14,4 \\
\hline 30 & 24,5 & 22,7 & 23,0 & 20,0 \\
\hline 35 & 30,1 & 30,1 & 31,7 & 31,7 \\
\hline 40 & 37,0 & 42,9 & 33,5 & 38,7 \\
\hline 45 & 40,3 & 42,1 & 40,2 & 56,9 \\
\hline 50 & 40,5 & 42,3 & 47,7 & 73,2 \\
\hline 55 & 39,6 & 42,3 & 50,0 & 83,5 \\
\hline
\end{tabular}

Comparando-se os dados da Tabela 8 frente aos da Tabela 9, alguns números mostraram alterações. Todavia, o comportamento geral foi o mesmo. Para cada frequência, o ângulo de fase acresceu com a temperatura até atingir determinado patamar, o que indica aumento da predominância viscosa do material. Em que 
pese a discrepância dos resultados para a frequência de $20 \mathrm{~Hz}$, já discutida anteriormente, apresentou ângulos de fase próximos do valor máximo $\left(90^{\circ}\right)$, representativo dos materiais puramente viscosos. Em geral, independente da frequência, para temperaturas superiores a $45^{\circ} \mathrm{C}$, comum nos pavimentos asfálticos de Manaus (por longas horas do dia durante vários meses do ano), o ângulo de fase indicou elevados valores, que evidencia um grande aumento da influência viscosa do material.

As deformações permanentes estão diretamente associadas à viscosidade, assim, quando se aumenta a resposta viscosa, maiores são as deformações não recuperáveis. Tais características influenciam consideravelmente nos defeitos observados nos pavimentos asfálticos - caso das vias pavimentadas de Manaus. Em suma, o trabalho mostrou que o aumento da temperatura até $55^{\circ} \mathrm{C}$, além de diminuir consideravelmente a resistência mecânica do compósito asfáltico estudado, retratada pela redução do módulo dinâmico, o torna muito mais suscetível às deformações permanentes, por aumentar a resposta viscosa do material, demonstrada pelo acréscimo do ângulo de fase.

Deste modo, a redução apontada na resistência do compósito asfáltico, representada pela variação do módulo dinâmico ao longo de um típico dia de calor regional, de 1.608MPa, no início da manhã $\left(25^{\circ} \mathrm{C}, 3 \mathrm{~Hz}\right)$ para 107MPa, durante várias horas do dia $\left(55^{\circ} \mathrm{C}, 1 \mathrm{~Hz}\right)$, que corresponde a uma queda de $93,3 \%$, é acompanhada de um aumento do ângulo de fase de $22^{\circ}$ para $39,6^{\circ}$, ou seja, em termos percentuais, a parcela do módulo dinâmico responsável pelo comportamento elástico é ainda menor e, durante várias horas do dia, sendo equivalente a apenas $82,45 \mathrm{MPa}$.

\section{CONCLUSÕES}

Os objetivos propostos foram alcançados com as análises realizadas, fruto da consulta à literatura, realização dos procedimentos de ensaios preparativos e de análise de propriedades mecânicas da mistura asfáltica selecionada, bem como de interpretação dos resultados. Em face das análises realizadas pode-se afirmar que:

Consideradas as condições locais de temperatura e tráfego, o módulo dinâmico pode apresentar grandes variações diárias, reduzindo-se de $1.608 \mathrm{MPa}$, início da manhã $\left(25^{\circ} \mathrm{C}, 3 \mathrm{~Hz}\right)$, para $107 \mathrm{MPa}\left(55^{\circ} \mathrm{C}, 1 \mathrm{~Hz}\right)$, situação que perdura por várias horas do dia.

A queda exemplificada é acompanhada de elevação do ângulo de fase de $22^{\circ}$ para $39,6^{\circ}$, o que além de diminuir a resistência total aumenta a resposta viscosa do material que, aliado a outras deficiências, como a carência de material pétreo, explica o excesso de problemas correlacionados a deformação permanente nos pavimentos asfálticos em locais de temperatura média elevada;

Em regiões de clima equatorial deve-se dar especial atenção à compatibilidade das normas que regem ensaios mecânicos com as temperaturas médias do local, a fim de melhor se retratar as condições reais dos pavimentos;

É viável a utilização de molde metálico para confecção de corpos de prova prismáticos, em formato de vigotas. Ressalta-se que a prensagem do material no molde deve ser acompanhada de vibração do conjunto (molde e massa asfáltica) para obtenção de uma compactação satisfatória;

É possível a obtenção, por meio de ensaios de flexão de vigas a quatro pontos, do módulo dinâmico de misturas asfálticas confeccionadas com ASAC, incluindo a situação em que as temperaturas foram mais elevadas, alcançando-se $55^{\circ} \mathrm{C}$, situação em que se necessita de cuidados adicionais em relação ao registro de interferências, pois a amplitude da carga é pequena em razão da grande diminuição da resistência mecânica do material.

\section{BIBLIOGRAFIA}

[1] KIM, Y. R. Modeling of asphalt concrete. United State of America: ASCE Press, 2009.

[2] VIEIRA, A., "Agregados de argila calcinada: uma alternativa para a pavimentação rodoviária na região amazônica”, In: Reunião Anual de Pavimentação, 32, [Anais eletrônicos], Brasília, 2000

[3] NASCIMENTO, R. R., Utilização de Agregados de Argila Calcinada em Pavimentação; Uma Alternativa para o Estado do Acre, Tese de M. Sc., Universidade Federal do Rio de Janeiro, RJ, Brasil, 2005.

[4] FROTA, C. A., SILVA, C. L., NUNES, F. R. G., "Análise do Comportamento Mecânico de Misturas Asfálticas Confeccionadas com Agregados Sintéticos de Argila Calcinada”, In: Jornadas Luso-Brasileiras de Pavimentos: Políticas e Tecnologias, 5, [Anais eletrônicos], Recife, 2006.

[5] FROTA, C. A., SILVA, C. L., NUNES, F. R. G., et al., "Desempenho mecânico de misturas asfálticas confeccionadas com agregados sintéticos de argila calcinada”, Cerâmica, v. 3, pp. 255-262, Set. 2007. 
[6] SANTOS, R. A., VIEIRA, A., OLIVEIRA, J. R. M. S., et al., "Produção de agregado artificial de argila calcinada para emprego em pista experimental no estado do Rio de Janeiro" In: Reunião Anual de Pavimentação/ Encontro Nacional de Conservação Rodoviária, 38, [Anais eletrônicos] Manaus, AM, Ago. 2007.

[7] SILVA, C. L., Módulo Dinâmico de Misturas Asfálticas Confeccionadas com Agregados Sinterizados de Argila Calcinada, Dissertação de M. Sc., Universidade Federal do Amazonas - UFAM, Manaus, AM, Brasil, 2011.

[8] SILVA, A. C. L., FROTA, C. A. "Estudo da viabilidade econômica para produção de agregado sinterizado de argila calcinada (Study of economic viability for production of sintered aggregate of calcined clay)." Cerâmica, 59, pp. 508-517, Abr./Jun. 2013.

[9] FEDERAL HIGHWAY ADMINISTRATION - FHWA. Superpave Fundamentals - Reference Manual (NHI Course \#131053). USA, 2000.

[10] PICANÇO, H. M., CARTAXO, E. F., FROTA, C. A., et al., "Refletividade, Radiação Solar e Temperatura em Diferentes Tipos de Revestimentos das Vias Urbanas no Município de Manaus (AM).” In: $5^{\circ}$ Congresso de Infraestrutura de Transportes, 5, [Anais eletrônicos], São Paulo, Ago. 2011.

[11] SHRP - "Superior Performing Asphalt Pavements (Superpave): The Product of SHRP Asphalt Research Program. Superpave Series Nº. 1”, Strategic Highway Research Program, Washington, DC,1994.

[12] SHRP - "Superior Performance Asphalt Pavements (Superpave). The Product of SHRP Asphalt Research Program. Superpave Series N ${ }^{\circ}$. 2” Strategic Highway Research Program, Washington, DC,1994.

[13] LYTTON, R. L. "Characterizing asphalt pavements for performance", Transportation Research Record: Journal of the Transportation Research Board, 1723.1, pp. 5-16, 2000.

[14] KING, M. H., Determination of Dynamic Moduli in Uniaxial Compression for North Caroline Hot Mix Asphalt Concrete, Tese de M. Sc., North Carolina State University, Raleigh, NC, 2004

[15] PAIS, J. C., et al. "Analysis of the variation in the fatigue life through four-point bending tests" ." In: Proceedings of the 2nd workshop on four-point bending, pp. 299-310, Guimarães, Portugal: University of Minho, Set. 2009.

[16] PAIS, J. C., HARVEY, J. T., "Four Point Bending” In: Proceedings of the 3nd workshop on four-point bending, pp. VII, Davis, USA: University of California, Set. 2012

[17] PRONK, A. C. "Theory of the Four Point Dynamic Bending Test-Part I: General Theory." Report PDWW-96-008, Deft University of Technology, The Netherlands (1996).

[18] HUURMAN, M., PRONK, A. C. "Theoretical analysis of the 4 point bending test." In: Proceedings of the 7th Int. RILEM Symposium Advanced Testing and Characterization of Bituminous Materials, Rhodes, Greece, Maio 2009.

[19] PRONK, A. C., "Description of procedure for using the Modified Partial Healing model”, In: Proceedings of the 3nd workshop on four-point bending, pp. 13-26, Davis, USA: University of California, Set. 2012

[20] FONTES, L., TRICHÊS, G., PAIS, J., et al., "Fatigue laws for Brazilians asphalt rubber mixtures obtained in 4 point bending tests." In: Proceedings of the 2nd workshop on four-point bending, pp. 149-156, Guimarães, Portugal: University of Minho, Set. 2009.

[21] GOUVEIA, L. T., FURLAN, A. P., PARREIRA, A. B. et al., "Considerações acerca da absorção de asfalto pelos agregados e sua influência na suscetibilidade à umidade", In: anais do XVIII Congresso de pesquisa e ensino em transportes, pp. 138-149, Florianópolis, Nov. 2004.

[22] BARBOSA, F. C. A. T., Contribuição para o estudo do desempenho de misturas betuminosas temperadas, Tese de M. Sc., Universidade Técnica de Lisboa, Portugal, 2012.

[23] SHINOHARA, K. J., Estudo do comportamento do concreto asfáltico modificado pelo polímero eva no módulo complexo e na fadiga, Tese de M. Sc., Universidade Federal de Santa Catarina, Florianópolis, SC, 2012.

[24] BARRA, B. S., Avaliação da ação da água no módulo complexo e na fadiga de misturas asfálticas densas, Tese de D. Sc., Universidade Federal de Santa Catarina, Florianópolis, SC, 2009.

[25] HUANG, Y H. Pavement analysis and design. Englewood Cliffs, N.J., Prentice Hall, 1993. 